\title{
NIETZSCHE SOBRE EL GENIO: SCHOPENHAUER, WAGNER Y EL DESPLAZAMIENTO DEL GENIUS POR EL «ESPÍRITU LIBRE» EN LOS AÑOS POSTERIORES A 1870*
}

\author{
Herman W. Siemens \\ Universidad de Leiden
}

RESUMEN: Este artículo examina la destrucción del concepto metafísico de genio en la mitad de la década de los años setenta del siglo XIX, entendido como una compleja diatriba con los conceptos de genio de Schopenhauer y Wagner. Las tensiones entre ellos relativas a la verdad y afirmación de la vida son lo que lleva a Nietzsche a reemplazar "genio» por «espíritu libre» (Freigeist) como su icono filosófico. Con el Freigeist, se arguye, Nietzsche finalmente rechaza el genio wagneriano en un movimiento que recupera y transforma características del genio de Schopenhauer.

Palabras clave: genio - espíritu libre

ABSTRACT: This paper examines the breakdown of Nietzsche's metaphysical concept of genius in the mid-1870's, understood as a complex Auseinandersetzung with Schopenhauer's and Wagner's concepts of genius. The tensions between them concerning truth and lifeaffirmation are what lead Nietzsche to displace genius with the «free spirit» (Freigeist) as his philosophical icon. With the Freigeist, it is argued, Nietzsche finally rejects Wagnerian genius in a move that recuperates and transforms features of Schopenhauer's genius.

Keywords: genius - free spirit

\section{INTRODUCCIÓN}

Las palabras Genie, Genius, Genial(-isch), Genialität aparecen más de 600 veces en los escritos de Nietzsche. Dan nombre a una de las vetas más ricas de su pensamiento, pero también una de las más complejas y contradictorias. Esto es debido en parte a las referencias fuertemente biográficas de las palabras para Nietzsche, en particular al trío Nietzsche-Schopenhauer-Wagner y a las vicisitudes de su relación. Pero para Nietzsche estas palabras son, además, un lugar privilegiado para la autocrítica filosófica y la reorientación, y como tal son altamente susceptibles de revisión, de giros de ciento ochenta grados y equivocaciones no resueltas.

Este artículo, basado en el lema del autor sobre «Genie/Genius» para el Nietzsche-Wörterbuch ${ }^{1}$, trata de utilizar los resultados de esta investigación para

* Agradezco a Luis E. de Santiago Guervós la tarea de traducir este artículo al español.

1. A cargo de P. J. M. Van Tongeren, G. Schank, H. W. Siemens et al., 2004. El vol. I (Abbreviatur -Einfach) fue publicado en 2004. La entrada «Genie» aparecerá en el vol. II, cuya publicación está prevista para 2008. 
consignar alguna de estas complejidades. Entre ellas señalaré especialmente las discrepancias, tensiones y revisiones que marcan el concepto de genio de Nietzsche durante el colapso del concepto metafísico de "genio" en el núcleo de $E l$ nacimiento de la tragedia en el curso de los años posteriores a 1870. Con el creciente distanciamiento de Wagner en este período, Nietzsche se ocupa de una autocrítica intensa y de una reorientación filosófica que llega a la fruición en Humano, demasiado humano. Cuando este proceso se examina a través del prisma del "genio», puede ser rastreado a través de tres líneas de pensamiento relacionadas, que llegan a dominar su uso del término en estos años: la pluralizacón del genio sobre el modelo del agón griego; la cuestión de la recepción y del discipulado activos; y el desplazamiento del genio por el «espíritu libre» (Freigeist) como icono filosófico de Nietzsche. En este artículo me centraré sobre esto último preguntando: ¿cómo se ha de entender el desplazamiento del genio por el «espíritu libre» como la figura icónica del pensamiento de Nietzsche? ¿Es el «espíritu libre» radicalmente opuesto al «genio», el signo de su rechazo, o se entiende mejor como una reconceptualización del «genio», conectado con él en lo esencial? Rastreando el fracaso del concepto metafísico de "genio» en Nietzsche desde GT, a través de Schopenhaner como educador (SE), a favor del «espíritu libre» en MA, trataré de mostrar que, junto a las rupturas, hay también continuidades profundas entre los conceptos de «genio» y «espíritu libre». Argüiré que el «espíritu libre» viene a parecerse menos a un rechazo del "genio» y más a la transformación de un vínculo inquebrantable con el "genio» por parte de Nietzsche. En este sentido, el concepto de «genio» también vierte luz sobre el cambio desde la primera fase del pensamiento de Nietzsche a la segunda, y ayuda a corregir toda oposición demasiado drástica entre la metafísica impetuosa de GT y la fría luz de la razón crítica en MA.

A pesar de las complejidades, discrepancias y equívocos en el concepto que tiene Nietzsche del genio como individuo, sería erróneo pensar que en el pensamiento de Nietzsche no se da una imagen coherente de «genio». Un análisis sincrónico de este concepto de "genio» muestra que hay cuatro características que son consistentemente afirmadas a través de los escritos de Nietzsche:

1) El genio es un tipo creativo-legislador:

El genio es un creador de nuevas visiones, nuevas obras, nuevos valores

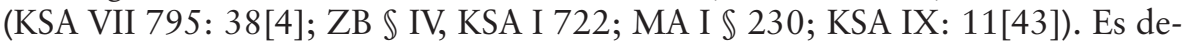
cir, el genio es y se siente intempestivo (SE $\mathbb{3}$, KSA I 351; GD, «Incursiones...», $\mathbb{S} 44$, KSA VI 145); jurídicamente, es un criminal, ya que al crear nuevos valores, o más bien un nuevo estándar o ley de valorar, rompe con las leyes y estándares recibidos (GD, «Incursiones...», $\mathbb{S} 45$, KSA VI 148; KSA XI: 25[259]; KSA XII 406: 9[120]).

2) El genio es un tipo económico:

Como creador, el genio es un derrochador de energía sobreabundante. Es decir, el genio es un tipo económico, alguien que puede permitirse odiar y crear, porque dispone de los enormes recursos que esto requiere (KSA VIII 91, 5 [180];

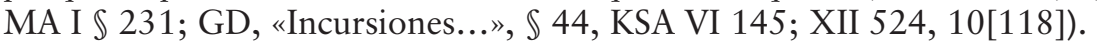

3) El genio es un tipo voluntarista:

Más que una energía o fuerza puramente fisiológica, el genio requiere fuerza de voluntad para coordinar, condensar y canalizar su energía en actos creativos 
de legislación (M $\ 548 ; 10[118] 12)$. Es decir, el genio es un tipo voluntarista: «Querer una meta sublime y los medios para alcanzarla» (VM $\$ 378$ ).

4) El genio es un tipo formal:

Finalmente, es una cuestión de plenitud creativa de la voluntad, no sólo de fuerza (10[118] 12). Es decir, el genio es un tipo formal que encarna y conjuga

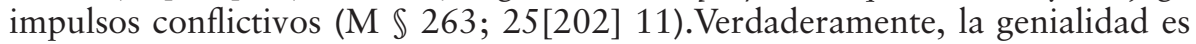
una cuestión de «amplitud y multiplicidad», de «totalidad en muchas cosas» (JGB \$212): como la forma de vida más rica y más compleja (14[133] 13), el genio coordina un rango máximo de perspectivas, esquemas de valores conflictivos e impulsos.

\section{LA CRÍTICA NIETZSCHEANA DEL GENIO EN HUMANO, DEMASIADO HUMANO}

MA se caracteriza por una crítica concentrada y metodológica del genio. La crítica del genio, y la adoración o culto del genio (Genieverehrung), no es de ningún modo confinada a este texto, sino que es uno de los temas más persistentes en el período de la vida de Nietzsche en que se preocupa del concepto de "genio", desde 1879-1881 hasta 1887. Pero incluso en MA, en donde la crítica de Nietzsche es más concentrada, sería equivocado leer esa crítica como un rechazo total del Genie, o como un fenómeno o un concepto (normativo) ${ }^{2}$. El interés principal de Nietzsche no es de ninguna manera demoler, sino desmitologizar el genio, es decir, deflactarlo o reducirlo a cualidades y condiciones puramente humanas, analizando el «devenir» o la «génesis» ${ }^{3}$ de sus obras. No solamente hay un buen número de usos positivos de Genie $e^{4}$. Los blancos de la crítica de Nietzsche son sumamente específicos: el concepto wagneriano de genio central para la metafísica de artista del joven Nietzsche y la «superstición» del genio cultivada por Wagner; es decir, no el genio como un fenómeno natural o cultural, sino Genie como una construcción ideológica que sirve a determinadas fuerzas político-culturales y a motivos ${ }^{5}$ psicológicos dudosos. La crítica del Genie y la Genieverehrung en MA es en gran parte una crítica de Wagner y del culto a Wagner, con sus apuntalamientos ideológicos y religiosos ${ }^{6}$. Un modo de entender la posición de Nietzsche en MA es centrarse sobre el signo más visible de su rechazo del genio, la figura del espíritu libre y preguntar: ¿cuál es exactamente la relación del Freigeist y el Genie? ¿Se opone radicalmente el Freigeist al Genie? ¿O su relación es más compleja de lo que parece? ¿Y cuál está en juego al cambiar uno por otro? ¿Cuáles son los problemas filosóficos que informan su relación? En orden a con-

2. Cf. Heller 1972: 38 s.; Politycki 1989: 215 ss.

3. Para "devenir» (Werden), cf. MA I $\int 145$, KSA II 141; para «génesis» (Entstehungsgeschichte), cf. KSA X: 16[14]; MA I $\mathbb{S}$ 231, 252, KSA II 194, 210; KSA VIII: 24[2]; cf. MA I $\$ 258$, pp. 212 s.; Polyticki 1989: 216 ss.

4. Por ejemplo, eleva y libera a su público: MA I $\$ 168$, KSA II 157; KSA VIII: 29[19]; VM \407, KSA II 533; también, MA I $\ 157$, KSA II 148.

5. Cf. MA I $\ 231$, KSA II 194; EH (MA) $\mathbb{1}$ 1, KSA VI 323; KSA XII: 9[178] (cf. KSA XIII: 14[182]); M $\int 548$, KSA III 318; KSA IX 106: 4[18]; KSA XII: 10[153]; KSA XIII 514, 528 s.: $16[82], 17[7]$.

6. Esto no fue pasado por alto por Wagner, quien se quejó de la crítica de quienes «echaron por la borda todo concepto de Genie como un error básico» (citado en Vogel 1966/21984: 218). 
signar estas cuestiones, debemos comenzar examinando las dos influencias clave en el concepto de genio del joven Nietzsche: Schopenhauer y Wagner.

\section{EL GENIO EN SCHOPENHAUER Y WAGNER}

El concepto de genio es rico en referencias biográficas. Esto no sólo se aplica a Nietzsche $^{7}$, sino especialmente a Schopenhauer y Wagner. Schopenhauer es un "genio enérgico y sobrio», según el relato de Nietzsche de su primer encuentro «demónico» con su obra, en donde habla, en el idioma propio de Schopenhauer, del «ojo del sol del arte completamente desinteresado» y de «un sobrio [...] autodesprecio [...]» (BAW III 298: 1867-1868). En una línea similar, la percepción inicial de Nietzsche de Wagner como un Genie schopenhaueriano encarnado está documentada en varias cartas, en donde la intempestividad de Wagner, su «idealidad absoluta» y la "proximidad de lo divino» son enfatizadas ${ }^{8}$. Es impresionante en estos relatos ver cómo Nietzsche utiliza los propios conceptos de genio de Schopenhauer y Wagner para describir sus personalidades y su obra. Esto se extiende al pensamiento filosófico de Nietzsche a principios de los años setenta, dominado por un conflicto complejo con los conceptos de genio schopenhaueriano y wagneriano.

\subsection{El genio en Schopenhauer}

Muchas características adscritas por Schopenhauer a los genios ${ }^{9}$ individuales se vuelven a dar a lo largo de los escritos de Nietzsche, en contextos tanto afirmativos como críticos. Estas incluyen la contradicción o conflicto de ellos con sus épocas; su existencia marginal y soledad profunda; su sensibilidad; sus naturalezas apasionadas, afectos poderosos y superexcitabilidad (überspannte Stimmungen); sus voluntades titánicas; su intenso sufrimiento; melancolía y proximidad a la locura causadas por desilusiones amargas (cf. Barbera 1992/1993: 60); así

7. Cf., por ejemplo, la carta de M. v. Meysenbug de 7.6.1878, KSA XV 86 s.; también la observación crítica de Rohde a Overbeck en su carta de 31.5.1879, KSA XV 102. Según la hermana de Nietzsche, Elisabeth, «el consejero privado Ritschl terminó una carta dirigida a Basilea con estas palabras: 'En una palabra, Nietzsche es un genio'» (citado en Vogel 1984: 13), un cumplido posterior devuelto por Nietzsche (EH, «Por qué soy tan inteligente», $\mathbb{9}$, KSA VI 294, sobre Ritschl como «el único erudito genial»). Genie/Genius aparecen en contextos donde Nietzsche se refiere a sí mismo, con diferentes valoraciones. A veces son afirmados y reclamados por Nietzsche, especialmente en los textos tardíos (EH, «Por qué soy un destino", $\mathbb{S} 1$, KSA VI 365; 29[5] 11; 16[80] 13; también

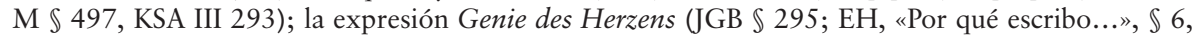
KSA VI 307) es usada para denominar la filosofía dionisíaca de Nietzsche, y Genie es frecuentemente aplicado a sus «escogidos lectores» (EH, «Por qué escribo...», $\mathbb{1}$, KSA VI 300), especialmente en las últimas cartas; cf. el borrador de carta a Stein de 1885 en KSA XV 145: "Es difícil conocer quién soy yo; esperemos cien años — quizás haya para entonces algún genio conocedor de los hombres que exhume al señor Nietzsche». Pero Genie/Genius son también rechazados, especialmente en textos de los años setenta (23[156], 30[9] 8; 1[120] 9; 16[10, 14] 10). En EH, Genie en su significado moderno se identifica con el opuesto idealista al Übermensch; mientras que en notas no publicadas para Za, Genie se identifica afirmativamente con el Übermensch (KSA X 422: 13 [1]; KSA X: 4[244] 10; cf. también KSA VIII: 29[16]), aunque se cuestiona su existencia/posibilidad.

8. Cf. carta de 4.8.1869, KSB III 35 s. También 25.8.1869, KSB III 46; y KGB I/3 321. Cf. asimismo la carta a Cosima de 19.6.1870, KGB II/1 125 y Vogel 21984: 41 s.

9. Cf. WWV I, p. 36; WWV II, p. 31; también HN; Schopenhauer 1985; Frauenstädt 1863. 
como el carácter teorético del genio, su veracidad (Wahrhaftigkeit), unido a la inutilidad del genio y del conocimiento genial para la vida práctica ${ }^{10}$. La doctrina central de Schopenhauer del «conocimiento sin voluntad» (willenlose Erkenntniss), la perspicacia intuitiva anormal hecha posible por un intelecto excesivo y su separación de la voluntad, se muestra en numerosos textos del joven Nietzsche $^{11}$. También aparece indirectamente, como en la Monströsität per defektum usada para describir a Sócrates como el genio de lo negativo en GT $\mathbb{S} 13$, que ha de leerse como un eco crítico del monstr[um] per excessum, utilizado por Schopenhauer (WWV II 31) para describir los excesos del intelecto requerido por el conocimiento genial. Desde 1876 en adelante, la doctrina del conocimiento sin voluntad (willenlose Erkenntniss) se convierte en el foco de una crítica intensiva y autocrítica, como cuando Nietzsche escribe:

Además, la sabiduría no me ha caído del cielo, pues no soy ningún «genio», no tengo una mirada intuitiva para ver por un agujero a través del manto de la apariencia. El ejemplo de Schopenhauer puede servir de advertencia: se equivoca en todos lo puntos en los que se tenía por un «genio» ${ }^{12}$.

Un punto crucial se alcanza en $\mathrm{M} \ 497$, en donde se identifica a Schopenhauer con un genio egocéntrico, incapaz de "volar por encima de sí mismo" (über sich hinausfliegen), en contraste con Platón, Spinoza y Goethe. Según Heller ${ }^{13}$ Nietzsche llega a leer la separación de intelecto y voluntad en el concepto de genio de Schopenhauer como un conflicto en el mismo Schopenhauer entre voluntad y negación de la voluntad, realismo e idealismo, vida y conocimiento, que a su vez informa la exploración de Nietzsche del conflicto en lo individual como dividuum.

En los escritos de Nietzsche (especialmente entre 1887-1888), la doctrina de Schopenhauer de la separación se identifica con la moralidad de la autonegación (Entselbstung) ${ }^{14}$ y el nihilismo ${ }^{15}$. Como un ideal epistémico y ascético, el principio de la «intuición desinteresada» es repetidamente criticado bajo el signo del genio en conexión con la cuestión genealógica: ¿de dónde (woher) procede la «voluntad para la verdad» (Wille zur Wahrheit), dado que la «voluntad para la mentira» (Wille zur Lüge) da la primacía a la vida? ${ }^{16}$. Sin embargo, estas críticas

10. Sobre Weisheit, más bien que Klugheit, cf. KSA VII: 14[15], 18[3]; M $\int 308$. De vez en cuando Nietzsche adscribe sin embargo una orientación práctica al genio (por ejemplo, M $\$ 452$ ), y tiene en cuenta las formas militares, psicológicas y políticas o tipos de genio. Según Ottmann, Nietzsche busca unificar cultura y política en SE a través de la figura del genio tanto Schöpfer como Täter, a costa de reducir la Tat a una Kulturtat (Ottmann 1987/21999: 89).

11. GT $\ 5$, KSA I 46 s.; KSA VII: 7[172, 174]; KSA VII 335: 10[1] sobre los «ojos del mundo»; KSA VIII 478: 24[2]; ZB \ IV, KSA I 729; también WL \$2, KSA I 889 s. sobre el «hombre intuitivo".

12. KSA VIII 462: 23[156]; cf. MA I $\$ 162$. Cf. también KSA VIII: 27[34], 30[9]; M $\ 544$, KSA IX: 4[99]; FW $\int 99 ; M ~ \$ 497$.

13. Heller 1972: 343 s. Cf. también pp. 39 s.

14. KSA XII: $10[118,153,99,77]$.

15. GD, «Incursiones...», $\mathbb{S} 21 ; 9[84] 12 ; 16[82], 17[1,7] 13$; cf. también 25[11], 27[79] 11 (1884).

16. Genie der Lüge, KSA XIII: 11[415], 17[3]; cf. KSA XII: 8[1]. Cf. también GM III $\ 12$ para el contraideal de Nietzsche de objetividad como una multiplicación de perspectivas. Para anteriores críticas (pragmaticistas) cf., por ejemplo: WL $\mathbb{1}$, KSA I 878; KSA VII: 19[253]; UB I $\ 6$, KSA I 394; KSA VII: 29[14, 144]; KSA VIII 132, 135, 170: 9[1]. 
no excluyen usos descriptivos y afirmativos del "genio" por parte de Nietzsche, que él asocia con gran inteligencia, y la obtención de perspectivas nuevas y singulares a lo largo de sus escritos.

\subsection{El genio en Wagner}

La influencia del concepto de genio de Wagner en el joven Nietzsche no ha de ser infravalorada. Como ha señalado Barbera ${ }^{17}$, su impacto se extiende tanto a las dimensiones culturales como a las metafísicas del pensamiento de Nietzsche en GT y en los primeros escritos póstumos. Mientras que se basa en el concepto de genio de Schopenhauer ${ }^{18}$, Wagner usa el término "para definirse a sí mismo» (FW $\mathbb{9} 99, \mathrm{KSA}$ III 455) y de ese modo se desvía notablemente del concepto de Schopenhauer. En contraste con la figura melancólica de Schopenhauer, resignada, que niega la vida, el genio de Wagner es una figura expansiva, extática y afirmativa ${ }^{19}$, de tal manera que Nietzsche puede escribir: «La obra de arte no es el objetivo de lo Uno primordial, sino el éxtasis genial del individuo» (7[139] 7; cf. 7[27, 100, 121] 7). Para Wagner, además, el genio individual representa una forma potenciada de la voluntad, su más alta manifestación. Basándose en la doctrina de Schopenhauer de la disarmonía consigo misma de la voluntad y su manifestación en el orden progresivo y conflictivo de los fenómenos, sitúa al genio en su cima, como resultado final y pináculo de todo conflicto penetrante de vida ${ }^{20}$. Como tal, sin embargo, el genio de Wagner también mantiene la clave de la redención desde el conflicto y el sufrimiento. En el ensayo Über Staat und Religion $^{21}$, en donde está más claramente desarrollada esta idea, el genio artístico se lanza como el creador de ilusiones poderosas (Wahngebilde, edle Täuschungen) que traduce la schopenhaueriana "seriedad de la vida» (Ernst des Lebens) en un «juego», mediante el cual se pone de manifiesto la nulidad del mundo (Nichtigkeit der Welt), aunque de manera inocua; pero lo hace como si fuera con una sonrisa. En este texto, el genio artístico ofrece a la comunidad de sufrientes una forma de redención inmanente a la vida (innerhalb des Lebens über diese erhebt) que le capacita para vivir y afirmar la vida, o como dice Nietzsche:

El genio actúa, por lo general, arrojando una nueva red de ilusiones sobre una masa, dentro de la cual ella puede vivir. Ésta es la influencia mágica del genio sobre los estratos inferiores. Al mismo tiempo, hay una línea ascendente hacia el genio: ésta desgarra sin cesar las redes existentes, hasta que finalmente, cuando se realiza el genio, se alcanza una meta artística superior ${ }^{22}$.

17. Barbera 1994: 217-233.

18. Kloss 1910: 82 ss.

19. Sobre el carácter erótico-extático del genio de Wagner, cf. Chytry 1989: 283 s. Sobre el rechazo por parte de Wagner del «pesimismo absoluto» y su transformación pasmosa de la ética negativa de Schopenhauer en una ética optimista y afirmativa del rejuvenecimiento moral y la redención del mundo sobre la base de la compasión, cf. Dinger 1892: 134-145.

20. Cf. KSA VII: 7[121, 160].

21. Wagner ${ }^{2} 1887$ : VIII, 3-29, esp. pp. 27 ss. Originalmente una carta escrita al rey Luis en 1864, el texto de Wagner fue publicado en 1873 con el título señalado arriba. Cf. las referencias entusiastas de Nietzsche en su carta a Carl von Gersdorff de 4.8.1869 y 2.3.1873, KSB III 36 y KSB IV 131.

22. KSA VII: 6[3]. Los términos Wahn, Wahnvorstellung, Wahngebilde son también usados in- 
Está claro que estamos lejos de un genio solitario y nada práctico, como en Schopenhauer, que subsiste marginalmente en la sociedad. A través de una síntesis peculiar del genio individual con el «genio de la especie» (Genius der Gattung $)^{23}$, Wagner lleva la figura del genio al mismo centro de la vida cultural y política, y le proporciona una meta eminentemente práctica, la de hacer posible vivir y afirmar la vida para la comunidad humana.

\subsection{Wagner contra Schopenhauer en el concepto de genio de Nietzsche}

Las tensiones entre los conceptos de genio entre Wagner y Schopenhauer generan los problemas centrales para las reflexiones de Nietzsche sobre el genio a principios de los años setenta: ¿̇uál es la meta de la educación (Bildung), de la cultura, del Estado y de la comunidad humana en general? ¿Puede el genio ser institucionalizado o politizado (a lo Wagner), o es necesariamente marginal ${ }^{24}$ ? Y sobre todo, la cuestión de la afirmación, y su relación con la verdad: ¿debe ser negada la existencia? ¿O puede ser justificada y, si es así, bajo qué condiciones? Este problema está implícito, pero no está puesto de relieve como tal en GT. En SE, alcanza el punto álgido y en MA encuentra una resolución que deja cuestiones importantes abiertas en la figura del «espíritu libre» (Freigeist). Estos cambios pueden ser comprendidos como una interacción compleja entre el genio wagneriano y el schopenhaueriano. Con el concepto de Freigeist trataré de mostrar que Nietzsche finalmente rechaza el genio wagneriano en un movimiento que recupera (pero también transforma) características del genio de Schopenhauer.

\section{EL NACIMIENTO DE LA TRAGEDIA}

GT está marcado por una relación sumamente inestable entre verdad y arte. Por un lado, el arte se sitúa bajo el signo de la ilusión (Wahn) wagneriana, como una ilusión que cura la herida de la existencia y nos seduce para vivir:

Es un fenómeno eterno: mediante una ilusión extendida sobre las cosas la ávida voluntad encuentra siempre un medio de retener a sus criaturas en la vida y de forzarlas a seguir viviendo. A éste lo encadena el placer socrático del conocer y

tensamente por Nietzsche al principio de los años setenta en conexión con la teoría de la Wahn de Schopenhauer (véase la nota siguiente). Esto se ve especialmente en KSA VII, cuadernos 5 y 7 , pero cf.

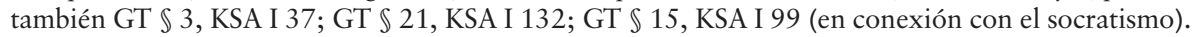

23. La expresión Genius der Gattung es usada por Schopenhauer en su metafísica del amor sexual (WWV II $\mathbb{S} 44$ ) para describir un mecanismo de decepción (Wahn), por el cual los individuos sirven a los intereses de la especie (Gattung) persiguiendo los que a ellos les parecen objetos de sus propios deseos. En Über Staat und Religion de Wagner ese concepto aparece como el «espíritu de la especie» (Geist der Gattung) en el contexto de su descripción de la teoría de la Wahn de Schopenhauer. El joven Nietzsche también lo aplica al arte. Como el dionisíaco Einssein im Genius der Gattung, opuesto a la individuación apolínea y a la medida (Maass), nombra etwas Nie-empfundenes, un sentido extático de la comunidad que necesita un nuevo orden simbólico, no apolíneo, identificado por Nietzsche con el Tanzgeberde (DW $\mathbb{S} 4$, KSA I 577; también, KSA I 574; GT $\$ 2$, KSA I 33), pero asimismo con el Ton $(3[21,37] 7)$.

24. Cf. KSA VII: 9[130] sobre el genio «apolíneo» frente al «dionisíaco»; también Ottmann 1987: 45 . 
la ilusión de poder curar con él la herida eterna del existir, a aquél lo enreda el seductor velo de belleza del arte, que se agita ante sus ojos, al de más allá, el consuelo metafísico de que bajo el torbellino de los fenómenos, continúa fluyendo indestructible la vida eterna (GT $\mathbb{1 8}$, KSA I 115 s.).

Los tres grados de la ilusión (Illusionsstufen) según Nietzsche en este pasaje incluyen el arte trágico y la cultura, de manera que la función de la tragedia es clara: seducirnos a vivir engañándonos para liberarnos del displacer de la existencia (über diese Unlust hinwegzutäuschen). Esto contrasta fuertemente con otras partes de GT, sobre todo con la sección precedente 17, en donde el arte trágico es concebido como el medio privilegiado para la afirmación de la vida $y$ de la verdad dionisíaca:

Nosotros mismos somos realmente [wirklich], por breves instantes, el ser primordial, y sentimos su indómita ansia y su indómito placer de existir [...]. A pesar del miedo y de la compasión, somos los hombres que viven felices, no como individuos, sino como lo único viviente, con cuyo placer procreador estamos fundidos (GT \17, KSA I 109).

La fusión, muy real (wirklich), inmediata y gozosa, con la voluntad del mundo (Weltwille) descrita en este pasaje no podía estar más alejada de la afirmación wagneriana a propósito de la ilusión o los grados de la ilusión con la que comienza la siguiente sección del texto. Pero aquí también, en el mismo corazón de la metafísica de artista de Nietzsche, es palpable otra vez la influencia de Wagner.

Uno de los grandes puzles que tenemos en GT es cómo Nietzsche puede proponer una metafísica formulada en términos cuasi schopenhauerianos justamente pocos años después de la crítica devastadora de la metafísica de la voluntad de Schopenhauer, emprendida en las notas de «Sobre Schopenhauer»" ${ }^{25}$. Esta crítica conserva claras huellas de las lecturas que hizo Nietzsche de Haym, Lange y Überweg ${ }^{26}$, y apunta sobre todo a la incoherencia del concepto de voluntad de Schopenhauer tanto como un principio inmanente para descifrar «el texto indescifrable que llamamos mundo» (ibid., 355) como una "cosa en sí» trascendente, completamente separada de sus apariencias en el mundo fenoménico (ibid., 356). Como observa Barbera, esta crítica da cuenta de los esfuerzos subsiguientes de Nietzsche a inicios de los años setenta para retener el sentido primero, inmanente de la «voluntad» (a menudo puesta entre comillas), y explotar su función hermenéutica sistemática, mientras la despoja de su significado trascendente y metafísico ${ }^{27}$. Por otro lado, tal y como indica el pasaje citado más arriba de GT, Nietzsche también mantiene un apego enigmático a la metafísica en este período. Y es aquí donde entra en juego el concepto de genio de Wagner; pues, en palabras de Barbera, permite a Nietzsche «llenar el vacío metafísico» dejado por su primera crítica de Schopenhauer «con una ideología del genio» (ibid., 230). El genio wagneriano no solamente copia a nivel de la especie o género (Gattung)

25. «Sobre Schopenhauer», de octubre de 1867-abril de 1868, en BAW III 352-370 (452-453 para el Nachbericht).

26. Cf. BAW III 452 s. (Nachbericht); Barbera 1994: 221 s., 226 s.

27. Cf. Barbera 1994: 220 s. para las referencias. Para una lectura no metafísica de la voluntad en el mismo período, cf. Allison 1985: 295-310. 
la producción de imágenes redentoras o «imágenes ilusorias» (Wahngebilde) por parte del ser primordial; realmente se fusiona con el ser primordial, sirviendo como centro de gravedad para la metafísica de artista de Nietzsche:

El genio sabe algo acerca de la esencia eterna del arte tan sólo en la medida en que, en su acto de procreación artística, se fusiona con aquel artista primordial del mundo; pues cuando se halla en aquel estado es, de manera maravillosa, igual que la desazonante imagen del cuento, que puede volver los ojos y mirarse a sí misma; ahora él es a la vez sujeto y objeto, a la vez poeta, actor y espectador (GT \$5, KSA I 47 s.; GT 67).

Este pasaje ilustra bien cómo para Nietzsche la figura del genio mantiene unidos el arte y la metafísica. Más aún, dicha figura cohesiona la misma metafísica de Nietzsche, y en su función, como vínculo unificador entre la esencia interior del mundo y el mundo fenoménico de la representación o apariencia, está el mayor débito de Nietzsche a las reflexiones de Wagner sobre el genio.

En los dos pasajes de GT $\$ 5$ y GT $\$ 17$ citados antes, destacan dos momentos: la fusión inmediata y afectiva con el ser primordial (Urwesen, Urkünstler), y la capacidad maravillosa del genio artístico de volver sus «ojos» hacia el interior e intuirse a sí mismo (sich selber anschauen) con clarividencia mágica. Ambos momentos, y la trasgresión de subjetividad o individualidad que los hace posibles, son sacados directamente de la descripción que hace Wagner del genio musical en su ensayo Beethoven ${ }^{28}$. En el preámbulo al ensayo, escrito en 1870 para celebrar el centenario del nacimiento del compositor, Wagner se dedica a ampliar y corregir la idea que Schopenhauer tiene del genio, de tal manera que pueda incorporar el estatus metafísico privilegiado de la música. Por un lado, Schopenhauer adscribe un estatus privilegiado a la música por encima de todas las artes como expresión directa de la voluntad, que precede a la representación y a todo conocimiento intuitivo del mundo. Por otro lado, su descripción del genio artístico permanece unida a su doctrina de las ideas en la capacidad del genio de intuir ideas a través de la separación de su intelecto anormal de la afectividad de la voluntad. Esta doctrina, arguye Wagner, no puede explicar un genio musical como el de Beethoven, ya que la música es «la expresión inmediata del afecto de la voluntad» (Wagner ${ }^{2} 1887: 71$ ) y que «la concepción musical» puede «no tener nada en común con la contemplación de una idea (ya que ésta se halla completamente ligada al conocimiento intuitivo del mundo)» (ibid., 68). Entonces, Wagner se inspira en la enseñanza de Schopenhauer de la «introspección de la conciencia», por lo cual la conciencia de sí mismo como voluntad llega a ser posible, a fin de volver a describir el genio musical en el estado de inspiración extática. A diferencia del artista plástico, cuya voluntad individual se extingue en la pura intuición de las ideas, el músico encarna la más alta excitación de la voluntad; sin embargo, es la «voluntad universal», no su voluntad individual, la que en el músico llega a la autoconciencia «más allá de toda intuición» y «por encima y

28. Wagner ${ }^{2} 1887$ : IX, 61-126. Sobre la influencia de este texto en Nietzsche, cf. Bruse 1984: 168-171; Kropfinger 1985: 9 ss.; Stein 1960; Borchmeyer 1982: 160 ss.; Janz 1981: I, $391,393$. Estoy en deuda con Menno Bogaard por haber destacado la importancia de este texto para la comprensión de la subjetividad musical en GT. Cf. Boogard 2001. 
más allá de todos los límites de la individualidad» (ibid., 72-73) ${ }^{29}$. Mientras que, como Nietzsche, quiere enfatizar el extático «desbordamiento de todos los límites de las apariencias» $\mathrm{y}$ «de la individualidad» en una fusión afectiva inmediata con «la voluntad omnipotente», Wagner insiste igualmente, como Nietzsche, en la clarividencia (Hellsichtigkeit) de la introspección de la conciencia del músico (ibid., 73-78). Lo más importante tanto para Wagner como para Nietzsche, es que esta autoconciencia musical inmediata consigue la unidad del mundo como voluntad con el mundo como representación: por encima y frente a los límites, divisiones y conflictos que marcan el mundo exterior de las apariencias, la expresión musical inmediata de la voluntad establece la identidad o unidad de nuestro ser interior como voluntad con las manifestaciones múltiples y divididas de la voluntad en las apariencias (ibid., 71-73).

Estas (y las adicionales) relaciones entre GT y el Beethoven también sugieren una respuesta al apego problemático de Nietzsche a la metafísica después del golpe de muerte deliberado en «Sobre Schopenhauer». Si bien Nietzsche rechaza el significado metafísico de la «voluntad» de Schopenhauer porque, como palabra, no es más que un símbolo para las representaciones (cf. KSA VII 361: 12[1]), recurre a la metafísica porque tiene en mente un medio de un orden totalmente diferente que ese de palabras o conceptos: la música. El apego de Nietzsche a la metafísica en GT no es un compromiso ontológico como tal, sino más bien un compromiso con el estatus único de la música: es el espíritu de la música —una expresión que se encuentra también en Beethoven (ibid., 80)— que hace posible la afirmación extática de la voluntad en el encuentro con su carácter verdadero en la tragedia. Sin embargo, como ya se señaló antes, esta posición se desestabiliza por la otra posición, inspirada en la teoría de la ilusión de Wagner, de que la afirmación hecha posible por el genio en el arte y la cultura trágicos se aprovecha de la ilusión y de la decepción. Si la tensión entre estas posiciones queda sumergida por las cualidades calidoscópicas de GT, sube a la superficie en SE, en donde alcanza un punto álgido en la descripción que Nietzsche da de «Schopenhauer como educador».

\section{SCHOPENHAUER COMO EDUCADOR}

En SE Nietzsche se ocupa del problema de la afirmación de la vida en el $\$ 3$, en donde Schopenhauer se presenta por primera vez como legislador filosófico:

Imaginémonos el ojo del filósofo posado sobre la existencia: quiere determinar de nuevo su valor. Pues éste ha sido el trabajo específico de todos los grandes pensadores, ser los legisladores de la medida, de las monedas y del peso de las cosas (SE $\$ 3, \mathrm{KSA}$ I 360/28).

Pero Nietzsche no va a ofrecer un relato fidedigno de Schopenhauer. En vez de eso, el pasaje envuelve una reflexión sobre el problema de Schopenhauer: ¿cuál es el valor de la vida?, ¿qué es una vida digna? Una reflexión que lo corrige. Nietzsche aborda la cuestión del valor de la vida, pero luego la corrige planteán\$6).

29. En GT este punto encuentra su más clara expresión en la descripción de la poesía lírica (GT 
dose la cuestión previa: ¿cuáles son las condiciones para un «juicio justo» (ein gerechtes Urteil) o «equitativo» del valor de la vida? Esta cuestión le lleva a consideraciones que exhiben una vacilación extrema entre los conceptos wagnerianos y schopenhauerianos de genio. Los polos de la vacilación de Nietzsche pueden ser esquematizados como sigue sobre la base del anterior análisis:

\begin{tabular}{|l|l|}
\hline \multicolumn{1}{|c|}{ GENIO EN SCHOPENHAUER } & \multicolumn{1}{c|}{ GENIO EN WAGNER } \\
\hline $\begin{array}{l}\text { Pensador: solitario, marginal, } \\
\text { extrainstitucional }\end{array}$ & $\begin{array}{l}\text { Artista: en el centro de la comunidad } \\
\text { y cultura humanas (fusión de Genie y } \\
\text { Genius der Gattung) }\end{array}$ \\
\hline $\begin{array}{l}\text { Veraz (wahrhaftig): } \\
\text { dedicado a la verdad }\end{array}$ & $\begin{array}{l}\text { Dedicado a la belleza: creador } \\
\text { de Wahnbilder, Illusionen, Trugbilder }\end{array}$ \\
\hline $\begin{array}{l}\text { Teorético (Richter des Lebens): } \\
\text { inútil para la vida práctica }\end{array}$ & $\begin{array}{l}\text { Práctico (Reformator des Lebens): } \\
\text { fuente y meta de la cultura }\end{array}$ \\
\hline Negación de la vida & Afirmación de la vida \\
\hline
\end{tabular}

El argumento desarrollado en este pasaje puede ser planteado en los siguientes términos: Nietzsche está de acuerdo con Schopenhauer en que la vida tal y como es no puede ser afirmada. Sin embargo, no continúa sacando la conclusión práctica de Schopenhauer de que la vida, por consiguiente, no debe ser. En vez de eso, cuestiona el punto de vista de este juicio de la vida, y arguye que un «juicio justo» requiere primero una transformación de la perspectiva que evalúa y una transformación de la vida misma en algo mejor. El problema es que estas transformaciones hacen que entren en juego recursos prácticos y estéticos, que comprometen la veracidad (Wahrhaftigkeit) del filósofo-legislador. El filósofo se ve abocado a elegir entre «el reformador de la vida y el filósofo, es decir: el juez de la vida» (Reformator des Lebens, Richter des Lebens); queda atrapado en "la discordia entre el deseo de libertad, belleza y grandeza de la vida, y el impulso por la verdad que pregunta solamente: ¿qué es la existencia digna? ${ }^{30}$.

No es difícil ver tras esta discordia la diferencia entre los conceptos de genio de Schopenhauer y Wagner. La preocupación expresada en estas líneas es si el legislador puede ser veraz (wahrhaftig) como Schopenhauer y, con todo, afirmar la existencia, o si la ilusión es necesaria para afirmar la existencia. Nietzsche está incómodo por la conexión que hace Wagner entre ilusión y afirmación, y con razón. Pues ¿qué valor tiene afirmar una vida digna, si está basada en un visión ilusoria de la vida? Hasta MA Nietzsche no romperá con esta ecuación de modo decidido y se liberará de la figura wagneriana del genio en favor del «espíritu libre». Pero en SE Nietzsche no es todavía capaz de dar este paso y permanece desgarrado entre Schopenhauer y Wagner. En su esfuerzo por escapar de la ecuación wagneriana de afirmación de la vida e ilusión, Nietzsche se retrotrae a la metafísica de Schopenhauer: a pesar de su esfuerzo por pensar la veracidad del filósofo junto con la afirmación de la vida, termina negando la vida en su carácter como devenir. Estas tensiones se ponen de manifiesto en una ambigüedad crucial en el retrato que hace de Schopenhauer, algo que viene de una ambigüedad en

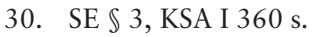


su uso de la palabra Zeit. La ambigüedad está entre el rechazo de Schopenhauer de lo presente (das Zeitgemäße) y su rechazo del tiempo mismo como una «madre falsa, vanidosa e indigna». La ambigüedad procede de la ambivalencia del uso que hace Nietzsche de la palabra Zeit cuando habla primero de la lucha de Schopenhauer contra el Zeit (en el sentido de «los tiempos, el presente»), y luego de su lucha contra el Zeit (en el sentido de «el tiempo, la existencia temporal, el devenir»). Consideremos las siguientes tres líneas al final del pasaje: «finalmente se demuestra que el presunto hijo del presente [Kind der Zeit] no es más que su hijastro». Aquí die Zeit significa los tiempos, el presente, la época. «De este modo Schopenhauer se alzó ya desde su primera juventud contra esa madre falsa, vanidosa e indigna, el presente (die Zeit)». De nuevo, die Zeit significa los tiempos, el presente, la época. Pero sigue a continuación:

Tan pronto como hubo vencido a la época en sí, tuvo que mirar también con ojos asombrados al genio que lleva en sí. El secreto de su ser le fue ahora revelado, la intención de esa madrastra, el tiempo [jener Stiefmutter Zeit], de ocultarle este genio fue frustrada, el reino de la naturaleza transfigurada era descubierto.

Aquí jener Stiefmutter Zeit (sin el artículo determinado: «die» Zeit) puede solamente significar el tiempo mismo. La lucha de Schopenhauer contra el presente, contra los tiempos, se ha convertido en una lucha contra el tiempo mismo, es decir, contra el devenir (Werden) en nombre del ser $(\text { Sein })^{31}$. Pero entones debemos preguntar: ¿la afirmación del ser (contra el devenir) constituye una afirmación o una negación de la vida? ¿Es posible que se pueda negar el devenir y afirmar la vida? ¿En qué sentido la exclusión del devenir es ser vivo? En su esfuerzo por escapar a la ecuación wagneriana de afirmación de vida e ilusión, Nietzsche se ve forzado a alinear la legislación filosófica (Wahrhaftigkeit) con el ser frente al devenir, es decir, con la negación de la vida.

\section{HUMANO, DEMASIADO HUMANO}

En MA renuncia a tratar de unificar los elementos schopenhauerianos y wagnerianos de su concepto de genio. La conexión wagneriana entre afirmación de la vida e ilusión es decididamente rechazada en la figura del espíritu libre. El rechazo del genio wagneriano lleva a Nietzsche a absorber — pero también a transformar - algunos rasgos del genio schopenhaueriano en el espíritu libre. Como sugiere Nietzsche, el espíritu libre, aunque se opone al genio wagneriano, no se opone al concepto de genio per se, que goza de una amplia trayectoria en su pensamiento, como ya he indicado. A continuación me concentraré en tres momentos de este cambio. Comenzando con una exposición de la oposición radical entre el espíritu libre y el genio wagneriano (a), indicaré entonces cómo Nietzsche construye elementos transformados del genio de Schopenhauer dentro del espíritu libre (b). En la sección conclusiva, trataré de mostrar cómo algunos problemas afrontados por el espíritu libre son tratados por Nietzsche sobre el modelo desmitologizado del genio desarrollado en MA (c).

31. Como el mismo Nietzsche parece conceder algunos años más tarde (1878): «Das größte Pathos erreichte ich, als ich den Schopenhauerischen Menschen entwarf: den zerstörenden Genius, gegen alles Werdende» (KSA VIII 493: 27[34]). 


\subsection{El Freigeist contra el genio wagneriano}

Es una vez más Barbera ${ }^{32}$ quien ha señalado la influencia — esta vez negativadel genio wagneriano en el concepto de Nietzsche del espíritu libre. Si Wagner entiende el genio como una forma intensificada de la voluntad, más aún, como la expresión directa del «afecto de la voluntad», la ruptura de Nietzsche con Wagner es tematizada como la liberación del espíritu libre de las pulsiones excesivas y violentas de la voluntad, algo que es posible por «la influencia del conocimiento purificador». La clave para el espíritu libre es su «buen temperamento», «su alma segura, mesurada y en el fondo gozosa», que se libera «de los lazos ordinarios de la vida», y que desea solamente "volar así libremente, sin temor, por encima de los hombres, de las costumbres, de las leyes y de las apreciaciones tradicionales de las cosas» (MA I $\mathbb{3} 34$, KSA II 55). Mientras que el genio wagneriano es activo y práctico, un «reformador de la vida», Nietzsche opone el espiritu libre al «hombre libre de acción» (ibid.). En medio del «aceleramiento monstruoso de la vida» en el presente, el espiritu libre recobra el valor de la vida contemplativa con su

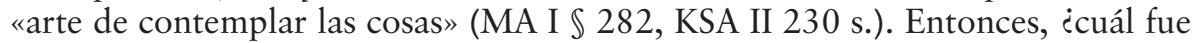
su relación frente a la vita activa? «Suavemente atado - no esclavo de sus acciones» (16[47] 8.294; cf. 17[42] 8). Pero como Nietzsche concede fácilmente, eso también quiere decir que «el espíritu libre es siempre débil, sobre todo en la acción; pues conoce demasiados motivos y puntos de vista y por ello su mano es poco segura y poco hábil» (MA I $\$ 230$, KSA II 193). Sin embargo, nada de esto quiere decir que el espíritu libre esté completamente apartado de los problemas y tareas prácticas. La enseñanza del espíritu libre es una «doctrina de la salud», un «autotratamiento antirromántico» (MA II Prólogo \$2, KSA II 371); aspira a una «ciencia realmente liberadora» que nos permite debilitar y dejar a un lado la necesidad de la metafísica y de la religión, poniendo de relieve su relatividad histórica y los «errores de la razón» sobre los que se apoyan (MA I \$27, KSA II 48); su objetivo no es imitar a la ciencia sino más bien «tomar el mando de todas las huestes de hombres de ciencia y eruditos y mostrarles los caminos y las metas de la cultura» (MA I $\$ 282$, KSA II 231), para suprimir las fronteras que impiden el paso a una "fusión de los seres humanos» (17[55] 8.306). En resumen, las cuestiones prácticas de la afirmación y del aumento de la vida permanecen como una perspectiva dominante en Nietzsche al describir el espíritu libre: «El espíritu libre vive para el futuro del hombre, de manera que inventa nuevas posibilidades de vida y pondera las antiguas» (17[44] 8.304).

Sin embargo, la fusión de Wagner del genio y el genio de la especie, capacitándole para situar al genio en el centro de la comunidad y de la cultura, está fuera de cuestión para el espíritu libre de Nietzsche. Su dedicación a la vida contemplativa le condena necesariamente a los márgenes de un presente inquieto; e incluso si su meta es tomar el mando sobre las comunidades científicas y eruditas, y mostrarles «los caminos y las metas de la cultura», solamente puede hacer eso «desde una posición aislada» (MA I $\$ 282$, KSA II 231) ${ }^{33}$. Sobre todo,

32. Barbera 1994: 231.

33. A lo sumo, el Freigeist disfruta de la compañía (imaginaria) de una pequeña comunidad de amigos y compañeros que comparten su manera de pensar (cf., por ejemplo, KSA VIII 306: 17[55]; MA I $\$ 38$, KSA II 61 s.; también MA I Prólogo $\$ 2$, KSA II 15). 
el espíritu libre rechaza la creación de ilusiones en el centro del concepto de genio de Wagner, quien es ahora desechado como un «enemigo de la verdad» (MA I \$ 635). Para el espíritu libre la razón crítica es soberana y, como en Descartes, aquél dedica su vida a seguir las «sendas de la verdad» (MA, «En lugar de un prólogo», KSA II 11) y a exponer el error y la ilusión. Sin embargo, esto tiene algunos problemas. La sospecha crítica cultivada por el espíritu libre revela que la ilusión ${ }^{34}$ no es sólo una característica del mal arte wagneriano, sino una condición omnipresente y necesaria para la vida y la afirmación de la vida. La vida del espíritu libre está desgarrada por el reconocimiento de que (la voluntad de) verdad y conocimiento están en radical contradicción con (las condiciones para) la vida y la afirmación de la vida, una intuición que jugará un papel central creciente en el pensamiento de Nietzsche, culminando en el concepto del genio de la mentira (11[415], 17[3] 13). Para el espíritu libre en MA, no queda claro cómo puede consagrarse a ambas, a la verdad y a la vida:

Pero inuestra filosofía no se convierte así en una tragedia? La verdad ¿no es hostil a la vida, a lo que es mejor? Una pregunta parece aflorar a nuestros labios y sin embargo no quiere que se pronuncie: si pudiésemos vivir conscientemente en la no-verdad. O si tuviésemos que hacerlo, ¿no sería preferible la muerte? (MA I $\mathbb{S}$ 34, KSA II 53 s.).

Cuando al final de este aforismo Nietzsche apela al «buen temperamento» del espíritu libre, es una respuesta desesperada y débil a una condición de desesperación causada por estas cuestiones. Habiendo argumentado que «lo ilógico es necesario para el ser humano» y parte de «todo lo que da valor a la vida» (MA I $\$ 31$ ); que «todos los juicios sobre el valor de la vida» (MA I $\$ 32$ ) y toda «creencia en el valor y dignidad de la vida» (MA I $\$ 33$ ) son ilógicos e indefensibles, en resumen, que «toda la vida humana está profundamente hundida en la no-verdad» (MA I $\$ 34$ ), esto le lleva a preguntarse si la prosecución de la verdad por el espíritu libre, imposibilitando las ilusiones y errores que hacen posible la afirmación y el aumento de vida, no le llevan necesariamente a desesperar del valor de la vida. En la repuesta de Nietzsche, su llamada a un «buen temperamento", el compromiso del espiritu libre con ambas, verdad y vida, no queda resuelto. Sin embargo, su oposición al genio wagneriano es implacable, y puede ser esquematizada como sigue:

\begin{tabular}{|c|c|}
\hline GENIO DE WAGNER & ESPÍRITU LIBRE DE NIETZSCHE \\
\hline $\begin{array}{l}\text { Sobreabundancia de voluntad/afecto de la } \\
\text { voluntad }\end{array}$ & $\begin{array}{l}\text { Liberación de los impulsos excesivos y } \\
\text { violentos de la voluntad (MA I } \$ 34 \text { ) }\end{array}$ \\
\hline Práctico, activo & $\begin{array}{l}\text { Opuesto al «hombre de acción» (MA I } \\
\text { 34); «suavemente atado» a la vida activa } \\
(16[47] 8,17[42] 8) \text {; «débil en } \\
\left.\text { la acción» (MA I } \int 230\right) \text {; primeramente } \\
\text { contemplativo (17[41] 8) }\end{array}$ \\
\hline
\end{tabular}

34. Nietzsche habla de Schein (apariencia), Lüge (mentira), Verlogenheit (mendacidad), Unwahrheit (no-verdad). 


\begin{tabular}{|c|c|}
\hline $\begin{array}{l}\text { Centro de la cultura y de la comunidad } \\
\text { humanas: fusión de Genie y Genius der } \\
\text { Gattung }\end{array}$ & $\begin{array}{l}\text { Marginal, «solitario» (MA I } \mathbb{S} 282 \text { ); } \\
\text { comunidad (imaginaria) de amigos }\end{array}$ \\
\hline $\begin{array}{l}\text { Creador de imágenes ilusorias; «enemigo } \\
\text { de la verdad» (MA I } \$ 635 \text { ) }\end{array}$ & $\begin{array}{l}\text { Soberanía de la razón crítica (sospecha, } \\
\text { desconfianza, probidad): liberación } \\
\text { de los errores e ilusiones }\end{array}$ \\
\hline
\end{tabular}

\subsection{El espíritu libre como genio schopenhaueriano transformado}

La oposición de Nietzsche a Wagner y al genio wagneriano en MA le devuelve a él y a la figura del espíritu libre a la cercanía del concepto que tiene Schopenhauer del genio. Esto se puede ver fácilmente en los rasgos descritos anteriormente: la soledad y la existencia marginal del espíritu libre (aunque cualificado por la persistente pluralización de Nietzsche del espíritu libre en una comunidad-en-soledad marginal); su (relativa) inacción y distancia de la vida práctica; y su dedicación contemplativa a la verdad y al conocimiento. Conexiones menos obvias, pero algo más específicas, incluyen la manera en que el carácter desarraigado del espíritu libre le capacita para contemplar el mundo empírico desde una distancia, como en un cuadro ${ }^{35}$, que Nietzsche llama el Genius der Meditation $($ MA I $\$ 282)$; y posiblemente también la unilateralidad del Genie, la tendencia a llegar a ser completamente absorbido en una única línea de pensamiento ${ }^{36}$. Sobre todo, el compromiso del espíritu libre a la verdad, unido a su reconocimiento de la necesidad de la no-verdad para la vida, le lleva más cerca de la negación de la voluntad o de la vida de Schopenhauer, más de lo que Nietzsche quisiera ${ }^{37}$. Sin embargo, nada de esto implica una regresión a la metafísica de Schopenhauer, tal y como se vio anteriormente en SE: la (auto-) crítica mantenida por Nietzsche en MA de la intuición metafísica privilegiada, adscrita (sea por Schopenhauer o por Wagner) al genio, da fe de esto. Para una comprensión de esta compleja deuda con el genio de Schopenhauer, merece la pena considerar dos notas del Nachlass de MA de 1878. Aunque no permite que se aproxime el espíritu libre al pesimismo de la voluntad o de la vida de Schopenhauer, Nietzsche habla de un «pesimismo del conocimiento» escéptico, lo cual, mientras vuelve el espíritu libre contra Schopenhauer y el genio, está en deuda con el «hombre schopenhaueriano» de SE:

35. Cf. la descripción del joven Schopenhauer de la besseres Bewusstsein que nos permite ver die ganze Erfahrungswelt wie in einem Bilde (HN II, 30), citado en Barbera 1992/1993: II, 58-77, 59.

36. Ésta es una característica enfática del genio en Schopenhauer (cf. Barbera 1992/1993: 59), que se encuentra en formas deflactorias en el contexto de la crítica de Nietzsche del genio en MA (por ejemplo, MA I $\$ 260$ ). Es difícil determinar si esto se le atribuye también al Freigeist. Por una parte, la orientación del Freigeist es ecuménica, no unilateral; por otra parte, la unilateralidad en la ciencia recibe un elogio cualificado (por ejemplo, MA I $\$ 251$, MA I $\$ 270$ ), y parece atribuirse al Freigeist (por ejemplo, MA I $\$ 231$, MA I $\$ 164$ ). Cf., sin embargo, la autocrítica en la nota retrospectiva de 1881: «Ist nicht unsere Denkfreigeisterei als ein übertriebenes / einseitiges Handeln aufzufassen, dem das Gegengewicht / abhanden gekommen ist? Wird nicht auch der Künstler häufig / durch sein künstlerisches Schaffen aus seinem Centrum geworfen? / Sind nicht Sich-verhehlen, Sichvergessen, Sich-verleugnen / die Gefahren des fruchtbaren Einsamen?» (KSA IX 93: 3[140]).

37. Cf. Heller 1972: 40. 
El hombre schopenhaueriano me empujó al escepticismo hacia todo lo venerado, exaltado, hasta ahora defendido (también hacia los griegos, Schopenhauer, Wagner), el genio, los santos. - Pesimismo del conocimiento. Mediante este rodeo llegué a lo alto, con los vientos más fríos. - [...] (27[80] 8.500).

En otra nota relacionada con ésta Nietzsche describe el pesimismo escéptico del conocimiento del espíritu libre en términos de un distanciamiento doble, no sólo del «hombre schopenhaueriano» de SE, sino también del «artista metafísico» wagneriano de RWB. La nota comienza: «Alcancé el máximo pathos, cuando esbocé al hombre schopenhaueriano; el genio destructor, contra todo lo que está en devenir». El placer destructivo de negar la vida en SE, nos dice Nietzsche, es lo que entonces dio origen a una necesidad opuesta de construcción, expresada en el elogio a Wagner en WB: "Como contrapartida necesitaba del artista metafísico que construye, que le proporciona a uno bellos sueños en medio de jornadas de trabajo incómodas». Sin embargo, el carácter ilusorio y onírico del arte de Wagner fue finalmente insatisfecho, dando origen a la necesidad de una contramedida: el recurso sobrio al escepticismo pesimista en MA: «El descontento con el pensamiento trágico potenciado. / ANTíDoto: crítica pesimista del pensamiento y del placer de pensar. Crítica del genio» (27[34] 8.493). Pero cel espíritu libre y su pesimismo cognoscitivo se oponen simplemente al genio, como sugiere esto?

\subsection{El espíritu libre como un caso especial del genio}

En esta última sección indicaré cómo un número de problemas clave afrontados por el espiritu libre son tratados por Nietzsche sobre el modelo del genio. Al hacer esto, sigo la propia sugerencia de Nietzsche en MA I $\$ 231$ de que el «nacimiento del espíritu libre perfecto» es tratado como un caso especial del «nacimiento del genio». Los problemas afrontados por el espíritu libre atañen a los rasgos del genio que va más allá del mismo MA y tiene un largo recorrido en la preocupación que tuvo Nietzsche con el genio a lo largo de su vida, como trataré de mostrar considerando dos ejemplos. Ellos conciernen: 1) al genio como un tipo económico, y 2) al genio como una fuente de nuevas visiones, nuevo conocimiento e intuiciones singulares y nuevas. En cada caso indicaré cómo, al formular y al consignar una dificultad o tarea específicas afrontadas por el espíritu libre, el pensamiento de Nietzsche planea dentro de líneas de pensamiento que son aplicadas al genio en MA y en sus escritos posteriores. Esto es especialmente así en el primer caso, es decir:

\subsubsection{El problema económico de energía y de resistencia}

Para el espiritu libre este problema es una consecuencia directa de su impulso dominante para emanciparse de la tradición y del peso de los prejuicios heredados. Con este impulso, está inmediatamente atrapado dentro de una posición de debilidad, y se plantea la cuestión: ¿de dónde ha de sacar el espíritu libre la fuerza necesaria para resistir tradición y consenso? ¿Cuáles son sus fuentes de energía? O como Nietzsche señala tan elocuentemente en MA I $\mathbb{S} 230$ : 
Espíritu fuerte. - Comparado con aquel que tiene la tradición de su lado y no necesita ningún motivo para su acción, el espíritu libre es siempre débil, sobre todo en la acción; pues conoce demasiados motivos y puntos de vista y, por ello, su mano es poco segura, está mal educada. Ahora bien, ¿̇qué medio hay de hacerlo relativamente fuerte, hasta el punto de poder sostenerse, al menos, y de no perecer sin consecuencias? ¿Cómo nace el espíritu fuerte? Ésta es, en un caso particular, la cuestión de la producción del genio. ¿De dónde procede la energía, la fuerza inflexible, la persistencia con que el individuo, frente a la tradición, trata de adquirir un conocimiento enteramente individual del mundo? (MA I $\$ 230$, KSA II 193).

Antes de preguntar cómo se ha de entender exactamente esta referencia críptica a la "producción del genio» en el contexto de MA, vale la pena señalar el paralelismo estricto con el problema de la energía planteado por el concepto de genio de Nietzsche como tipo económico (característica 1, véase p. 100 supra), es decir, como creador de nuevos valores que rompe con las leyes recibidas y los estándares. Este problema es expresado también en GD, donde encontramos

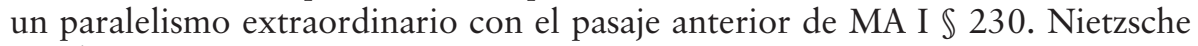
escribe:

Todos los innovadores del espíritu llevan durante algún tiempo en la frente el signo pálido y fatalista del chandala: no porque produzcan esa impresión, sino porque ellos mismos sienten el abismo terrible que los separa de todo lo tradicional y respetado. Casi todo genio conoce, como uno de sus desarrollos, la «existencia catilinaria», un sentimiento de odio, venganza y rebelión contra todo lo que ya es, lo que ya no deviene... Catilina - la forma de preexistencia de todo césar (GD, «Incursiones...», $\mathbb{S} 45, \mathrm{KSA}$ VI 148).

La enorme energía requerida para rebelarse contra las leyes y valores tradicionales informa la concepción del genio a lo largo de la vida de Nietzsche como un tipo económico: un derrochador que dispone de la energía desbordante requerida para sus esfuerzos creativo-destructivos (característica 2, véase p. 100 supra). Pero esto solamente plantea la cuestión de cuáles son las fuentes de energía. A lo largo de su obra, Nietzsche busca en dos direcciones una respuesta a esta cuestión, y las dos respuestas están ya apuntadas en el modelo desmitologizado del genio que desarrolla en MA.

En primer lugar, Nietzsche busca fuentes de energía y estímulos en la negatividad, coacción, resistencia, tensión, conflictos. En el Nachlass de MA escribe simplemente: "Los obstáculos, necesarios para producir el genio» (17[60]8). En MA I $\ 231$, en donde se establece explícitamente la conexión entre el nacimiento del espíritu libre y el genio, se explica esta idea por medio de la historia del preso que usa su ingeniosidad para buscar medios para evadirse y saca el máximo partido de los recursos o ventajas más pequeñas a su disposición. La naturaleza, continúa Nietzsche, despliega medios similares para producir el genio: "La naturaleza lo encierra en su calabozo y excita su deseo de liberarse hasta el último extremo» (MA I $\$ 231)$.

Ésta es solamente una de las tres imágenes desarrolladas en este aforismo con el propósito de deflactar el mito del genio. En todas las tres instancias, rasgos clave del mito del genio —originalidad y donación- son deflactados refiriéndolos a condiciones previas negativas. Por lo tanto, la «originalidad» es referida a un estado negativo de desorientación y es comparada a alguien que, 
completamente extraviado en el bosque, sigue tenazmente una dirección hasta que descubre una nueva senda que todavía era desconocida. En un movimiento similar, el «talento» o el «estar dotado» se refiere a una condición previa de una carencia, tal como la falta de un órgano particular por parte de alguien mutilado o lisiado, y la manera en que puede hacer que se desarrollen otros órganos en un grado excepcional para compensar esta falta. Para nuestro propósito, es importante la imagen del preso. Esto le permite a Nietzsche explicar los recursos energéticos necesarios para liberarse -como un genio o un espíritu libre- en términos de limitaciones previas o coacciones (la «prisión») y el modo en que las coacciones pueden actuar no solamente como inhibidores de la libertad, sino también como un estimulante para la autoemancipación. El genio y el espíritu libre emergen desde este aforismo, no como naturalmente dotados, energéticos y originales, sino como profundamente desorientados y severamente limitados por la naturaleza.

La tesis de la negatividad como una fuente de energía es luego ampliada en MA I $\mathbb{S} 233$ en un modo que sugiere una conexión nueva entre el genio y el espíritu libre. Aquí Nietzsche toma la enseñanza de la historia respecto a la creación del genio:

iMaltratad y torturad a los hombres! — así le grita [la historia] a las pasiones, envidia, odio y rivalidad - impulsadlos sin medida a unos contra otros, pueblo contra pueblo, y esto durante siglos. Entonces quizás brote a llamaradas, como de una centella separada en su vuelo de la terrible energía así incendiada, repentinamente el resplandor del genio; la voluntad, como un corcel enloquecido por las espuelas del caballero, estallará entonces y saltará a otro campo. - [...] (MA I $\mathbb{S}$ 233, subrayado nuestro).

Aquí la negatividad es en el sentido (no de falta o limitación, sino) de conflicto, lucha y tensión que se propone como la fuente de la «energía terrible» necesaria para las obras del genio y — podemos suponer- del espíritu libre. Esta idea tiene una prehistoria en el pensamiento de Nietzsche sobre el agón griego como forma limitada e institucionalizada del conflicto que él aduce para explicar la creatividad extraordinaria de la cultura griega, pero también en el pensamiento que se molesta porque las formas no limitadas del conflicto generen la energía necesaria para el genio... en detrimento del bienestar humano: Fatum tristissimum generis humani! ${ }^{38}$. Estas ideas tienen también una larga trayectoria posterior en el pensamiento de Nietzsche de la libertad bajo presión ${ }^{39}$.

Pero la negatividad no es la única fuente de energía que Nietzsche trata en conexión con el genio. Igualmente persistente es una llamada a la herencia y al poder acumulado, como en GD, «Incursiones...», $\mathbb{S} 47$, en donde el genio, como la belleza humana, es visto como «el resultado final del trabajo acumulado de generaciones», dado que «todo lo bueno es herencia: lo que no es heredado

38. Para el agón como un mecanismo para la «estimulación recíproca» (sich gegenseitig zur That reizen), cf. Homers Wettkampf (KSA I 783-792). Para el conflicto ilimitado como la fuente necesaria de energía, cf. KSA VIII: 5[180, 178, 185, 188] y MA I $\$ 235$.

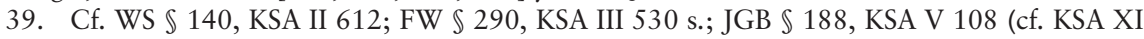
450 s.: 34[92]; JGB $\mathbb{2} 213$, KSA V 148, sobre necesidad y libertad); KSA X 97: 3[1]358; KSA XIII 224, 406: 14[14], 15[6]/13. Cf. también Siemens 2006. 
es imperfecto, es un comienzo...» (GD, «Incursiones...», \ 47, KSA VI 148 s.). En un aforismo anterior del mismo texto con el título "Mi concepto de genio", Nietzsche combina estas dos fuentes (negativa y positiva) de energía: la importancia de la herencia y del poder acumulado se unen a la idea de tensión (Spannung) a propósito de la teoría del «rescate» (Auslösung) ${ }^{40}$ de Robert Mayer, con la explicación:

Los grandes hombres, lo mismo que las grandes épocas, son materias explosivas en las cuales está acumulada una fuerza enorme, su presupuesto es siempre, histórica y fisiológicamente, que durante largo tiempo se haya estado juntando, amontonando, ahorrando y guardando con vistas a ellos, - que durante largo tiempo no haya tenido lugar ninguna explosión. Si la tensión [Spannung] en la masa se ha vuelto demasiado grande, basta el estímulo más fortuito para hacer surgir el "genio", la "acción», el gran destino en el mundo (GD, «Incursiones...», $\mathbb{4} 44, \mathrm{p}$. 120 / KSA VI 145).

Este aforismo culmina en que es quizás el estamento más fuerte de Nietzsche sobre el genio como un tipo económico, un «derrochador», compelido a agotarse por la «arrolladora presión de las fuerzas que se desbordan». La descripción del genio como un derrochador de energía desbordante en GD sirve a fines deflactorios similares a los de MA. En GD la adoración del genio por su «heroísmo» y «abnegación» es deflactada por la reinterpretación de estas virtudes como una compulsión fisiológica: la necesidad de descargar el exceso de energía: «Él se derrama, se desborda, se gasta, no se economiza, - de manera fatal, irremediable, involuntaria, como involuntario es el desbordamiento de un río sobre sus orillas».

En MA también se enfatiza la importancia de la herencia y del poder acumulado como fuente de energía. Lo que es más, Nietzsche pinta las mismas imágenes de las aguas caudalosas que casi se desbordan, cuando escribe:

Ninguna corriente de agua es por sí misma grande y caudalosa, sino porque recibe y conduce tantos afluentes secundarios. Lo mismo sucede con todas las grandezas del espíritu. Se trata tan sólo de que un hombre dé la dirección, que luego los afluentes seguirán necesariamente, y no importa que sea él mismo, desde el comienzo, pobre o rico de dones naturales (MA I $\$ 521$, KSA II 324).

Aquí la imagen de un río cuyas aguas caudalosas proceden de todos los afluentes que lo alimentan sirve como crítica deflactoria del mito del genio como una plenitud original y don de la naturaleza. Sin embargo, hay que notar que en este, como en algunos otros aforismos de MA, Nietzsche evita la palabra Genie, usando en su lugar términos como "grandeza», "grandezas del espíritu», "grandes espíritus». Creo que esto se entiende mejor como un paso deliberado de Nietzsche para elidir la diferencia entre el espíritu libre y su concepto de genio desmitologizado, como los referentes de estos términos. Esto vale también

40. En 1867 R. Mayer publicó una colección de artículos con el título Mechanik der Wärme que contiene, entre otros, su libro innovador Bemerkungen über die Kräfte der unbelebten Natur, de 1842, así como un nuevo artículo «Über Auslösung». Para una discusión del concepto de Mayer de descarga, cf. Mittasch 1952: 114 ss., y Aydin 2003: 157-163. 
para MA I $\mathbb{S} 164$, en donde de nuevo se acentúa la importancia de la herencia o genealogía como la fuente de energía para los «grandes espíritus»:

Incluso para los grandes espíritus hay probablemente más utilidad en darse cuenta de su fuerza y de su origen, en comprender por lo tanto qué cualidades puramente humanas han confluido en ellos, qué circunstancias felices han concurrido: así una energía que en un momento determinado encuentra su vía, una aplicación decidida a fines de detalle, un gran valor personal, luego la suerte de una educación que desde muy temprano le ofreció los mejores maestros, modelos y métodos (MA I \164, KSA II 155).

\subsubsection{El problema del conocimiento}

La (auto)crítica de Nietzsche de la intuición metafísica privilegiada adscrita por Schopenhauer y Wagner al genio es uno de los temas clave en MA. Como uno esperaría, las virtudes epistémicas del espíritu libre son a menudo opuestas a las pretensiones grandiosas del genio. Todavía hay momentos, sin embargo, en donde esta oposición es desplazada por otra figura del genio que encarna la episteme del espíritu libre. Un buen ejemplo de la descripción primera, en términos de oposición, se da en MA I $\$$ 635. En una referencia ligeramente velada a los conceptos de genio tanto de Schopenhauer como de Wagner, Nietzsche opone la anti-episteme de convicciones (Überzeugungen) fomentada por el genio al conocimiento auténtico orientado hacia una certidumbre (Gewissheit). Mientras que el conocimiento requiere desconfianzas instintivas, refinadas por una educación metodológica enfocada a la certidumbre, la autoridad epistémica reclamada por el autoproclamado genio fomenta el deseo vehemente de convicciones, «el fuego y las llamas» $\mathrm{y}$ «el incremento de fuerza»:

Cuanto más observamos con exactitud, más nos damos cuenta de que la gran mayoría de las personas cultas desean aún para el pensador convicciones y nada más que convicciones, y que tan sólo una pequeña minoría desea una certidumbre. Los primeros ansían ser fuertemente arrastrados para adquirir así ellos mismos un incremento de fuerza; los segundos, la minoría, tienen ese interés por las cosas mismas que prescinde de las ventajas personales, incluso de dicho incremento de fuerza [...]. En la medida en que el genio de esa especie mantenga el fuego de las convicciones y avive la desconfianza hacia el sentido prudente y modesto de la ciencia, es un enemigo de la verdad, aun cuando se crea el más destacado de sus amantes (MA I $\$ 635)$.

Si el «genio» es sinónimo de «enemigo de la verdad» en este aforismo, en el siguiente Nietzsche deshace esta identificación. En MA I \$ 636 se introduce otra «especie de genio", un genio que, como el «adversario de las convicciones», toma la oposición epistémica del espíritu libre a la convicción como su meta explícita o remite, en nombre de «la justicia». El interés ciclópeo del espíritu libre por el conocimiento se incorpora con esta figura del genio, pero solamente como una precondición para el ejercicio de la justicia, entendida como la voluntad de dar a cada uno lo suyo:

Es [esta especie de genio] un adversario de las convicciones, pues quiere dar a cada uno, vivo o muerto, real o imaginario, lo que es suyo - y para eso debe recono- 
cerlos con precisión; por eso pone cada cosa en la mejor luz haciéndolas girar con ojos atentos (MA I $\$ 636)$.

Pero como «genio de justicia», debe dar precisamente a su adversario su convicción, la suya propia: «Por último dará incluso a su adversario, a la ciega y miope 'convicción' [...] lo que conviene a la convicción — por amor a la verdad» (MA I $\left.\int 636\right)$. Lo que quiere decir Nietzsche exactamente con dar su propia «convicción» es aclarado en el siguiente aforismo. Pero nos da una pista la identificación de (la voluntad de) justicia con la (voluntad de) verdad con que concluye este aforismo. Está claro que Nietzsche tiene presente un sentido de verdad que es distinto del de certidumbre del espíritu libre. Nos recuerda, de hecho, la discusión anterior sobre la justicia. En HL $\mathbb{} 6$ Nietzsche describe la justicia como «la más alta y la más rara virtud» y continúa identificándola con la verdad, o más bien con «ese esfuerzo por la verdad que tiene sus raíces en la justicia» (HL $\mathbb{S}$, KSA I 286 s.). Pero en este pasaje también pone en claro que la virtud de la justicia es una «virtud imposible», casi demónica, es decir, una virtud virtualmente inhumana, o más que humana, que «consume trágicamente» a su poseedor. Si el genio de la justicia incorpora la episteme del espíritu libre, lo hace en nombre de una virtud más que humana: ¿a dónde nos lleva eso a nosotros que somos humanos, demasiado humanos?

En el siguiente aforismo, MA I $\$ 637$, Nietzsche aborda esta cuestión adoptando explícitamente un punto de vista humano, demasiado humano. Comienza distinguiendo una vez más la episteme de la certidumbre imparcial del espíritu libre de las convicciones: a través de un constante cambio de perspectivas, el espiritu libre puede evitar la solidificación de opiniones en convicciones fijas. Pero Nietzsche pasa luego a hacer justicia a las convicciones, a «darles lo suyo», insistiendo en que "nosotros somos seres mixtos, que tan pronto nos enardecemos por el fuego como nos enfriamos por el espíritu» (MA I $\mathbb{6} 637$ ). Como seres mixtos, somos arrastrados al fuego de las convicciones, y a la injusticia del conocimiento impuro. Pero como seres mixtos también somos arrastrados por el espíritu (libre) que está dentro de nosotros de opinión en opinión, y en el esfuerzo por adorar a la diosa justicia, llegan a ser «los nobles traidores de todas las cosas que pueden ser traicionadas - y, sin embargo, sin sentimiento de culpabilidad».

[Traducción de Luis Enrique de Santiago Guervós Universidad de Málaga]

\section{SIGLAS}

GT El nacimiento de la tragedia, introd., trad. y notas de A. Sánchez Pascual, Madrid: Alianza, 1997.

HN Schopenhauer, A., Der handschriftliche Nachlaß, ed. de A. Hübscher, Frankfurt a. M.: Kramer, 2 vols., 1966.

WWW Schopenhauer, A., Die Welt als Wille und Vorstellung, 2 vols.

BIBLIOGRAFÍA

Allison, D., 1985, «Nietzsche Knows No Noumenon», en D. O’Hara, Why Nietzsche Now?, Bloomington: Indiana University Press, pp. 295-310. 